\title{
HEMOTHORAX FOLLOWING PENETRATING THORACIC INJURY (GUNSHOT WOUND) IN GERIATRIC PATIENT: A CASE REPORT AND EMERGENCY MANAGEMENT
}

\author{
Gerardo AK Laksono ${ }^{1)}$, Ferdinand Erwin ${ }^{1)}$, Dyana Sarvasti ${ }^{2)}$, Paul L Tahalele ${ }^{\left.3)^{* * * *}\right)}$
}

\begin{abstract}
Introduction: Penetrating chest trauma is highly lethal. Studies have reported up to $60 \%$ mortality depending on the mechanism of injury. While penetrating chest trauma is less common than blunt trauma, it can be more deadly. High-velocity gunshot injury resulting in penetrating thoracic trauma in geriatric patients poses a significant challenge for the traumatic surgeon. Hemothorax is usually a consequence of penetrating chest trauma. It can be caused by intercostal arterial bleeding, especially the posterior part. Initial treatment, including chest tube drainage insertion, is needed to avoid lung compression and to assess future treatment needed.

Purpose: To report the patient survival from massive hemothorax caused by penetrating Thoracic injury caused by an air rifle, treated by chest tube insertion and posterolateral thoracotomy to take out the bullet several days after.

Case Report: 70-year male patient came to the Emergency Room (ER) Adihusada Hospital Surabaya with a penetrating chest injury caused by an air rifle on the right side of the chest. The patient had chest pain, shortness of breath, and hypoxia. By inserting a chest tube, emergency management was done by a general surgeon due to the massive right hemothorax. An immediate chest tube insertion was needed to overcome the patient's breathing problem to assess the future treatment needed. Chest X-ray and CT-Scan was done immediately after the patient's hemodynamic were stable. Three days after hospitalizing, the Cardiothoracic and vascular surgeon performed posterolateral thoracotomy to take the bullet out of the chest.

Conclusion: Seven days postoperatively, the patient was discharged from the hospital without any complications and stable hemodynamic. The patient went to the outpatient department for follow-up one week after.
\end{abstract}

Keywords: Chest injury, penetrating chest injury, gunshot injury, hemothorax

\footnotetext{
${ }^{1)}$ Student of Faculty of Medicine, Widya Mandala Surabaya Catholic University Indonesia, Jl. Kalisari Selatan No.1 Surabaya Email: gerardoagung@gmail.com

${ }^{2)}$ Internal Medicine Department, Faculty of Medicine, Widya Mandala Surabaya Catholic University Indonesia, Jl. Kalisari Selatan No.1 Surabaya

${ }^{3)}$ Surgery Department, Faculty of Medicine, Widya Mandala Surabaya Catholic University Indonesia, Jl. Kalisari Selatan No.1 Surabaya

*) President of International College of Surgeons Indonesia Section

**) President of Indonesian Association of Thoracic, Cardiac and Vascular-Endovascular Surgeons
} 


\section{INTRODUCTION}

The thoracic injury has became one of the most common reasons patient comes to the emergency department. Thoracic trauma accounts for up to $40 \%$ of trauma-related death. ${ }^{1,2}$ Thoracic trauma is divided into two categories blunt chest trauma and penetrating chest trauma. Blunt chest trauma is more common than penetrating trauma. The most common cause of blunt chest trauma is a vehicle accident; other causes include falls, act of violence, and blast injury. Higher morbidity in blunt trauma caused by vehicle accident is associated with high speed and lack of seat belt use. ${ }^{3}$

Gunshots and stabbing dominate the majority cause of penetrating trauma. Despite higher incidence, less than $10 \%$ of patients suffering blunt trauma to the thorax require surgical intervention, whereas $15 \%$ to $30 \%$ of patients sustaining penetrating chest injury need surgical intervention. Penetrating chest trauma is associated with a higher mortality rate. ${ }^{4}$ Among causes of penetrating thoracic injury, gunshot thoracic injury is the most fatal form of chest injury, leading to many morbidities. The risk of gunshot thoracic injury are heart penetration, blood vessel rupture, and lung injury that should be evaluated immediately, and any intervention, including surgical intervention, should never be delayed. ${ }^{5}$ Most penetrating injuries to the thoracic cavity can be managed by a simple procedure such as chest tube insertion; however, $15 \%$ of patients need definitive surgical repair. ${ }^{6}$

An elderly patient with thoracic trauma poses a significant challenge to a trauma surgeon. The challenge starts from diagnosing phase, preoperative phase, operative phase, and post-operative phase. Diagnoses can be delayed, and they do not tolerate complications as well as a young person. Delayed diagnosis can be caused by misleading criteria that are usually used for the general population. ${ }^{7,8}$

Hemothorax is common after thoracic injury, especially penetrating one. It can be caused by various sources of bleeding, such as disruption of the lung, pulmonary vascular hemorrhage, bronchial vessel bleeding, or injury to the intercostal vessels-most patients with stable hemodynamic penetrating hemothorax treated with chest tube insertion. However, patients who have persistent bleeding ( $>250 \mathrm{ml} / \mathrm{hr}$ for $2-4 \mathrm{hr}$ ) after chest tube insertion need a thoracotomy as bleeding control. ${ }^{9,10}$

\section{CASE REPORT}

A 76-year-old male came to the emergency department of Adihusada Hospital Surabaya with shortness of breath after a penetrating chest injury caused by a gunshot injury. The patient was conscious, with a heart rate of 120 beats per minute, blood pressure of $140 / 90 \mathrm{mmHg}$, respiratory rate of 32 breaths per minute, body temperature was 
36,9 oC, and peripheral saturation oxygen was $86 \%$ room air.

The physical examination was done immediately following the Advance Trauma Life Support (ATLS) protocol. From the physical examination, the patient's airway was fine. There was no partial nor complete obstruction of the airway. The patient's breathing was not fine. He had hypoxia, flared nostrils, and excessive use of accessory muscles. The chest examination revealed a gunshot wound with the entry point from the posterior part of the chest. The chest expansion was not normal, with asymmetry on the right side. Chest percussion revealed a dull sound on the right side, showed a fluidfilled on the right chest. From the patient's vital signs, it can be concluded that the patient was in Class I Hypovolemia Shock. On neurological examination, there were no motoric or sensory problems. There was no problem with exposure. For an adjunct to the primary survey, a chest radiograph was performed as a diagnostic tool. The chest radiograph showed massive fluid accumulation on the right side of the chest, suggesting hemothorax (Figure A-B). A foreign body with high opacity also identified a place in the posterior mediastinum through anterior-posterior position and lateral position chest X-ray. An immediate Chest tube insertion using a large-bore (24 F) tube through the fifth intercostal space in the midaxillary line done immediately by the general surgeon. After chest tube insertion was done, around $500 \mathrm{ml}$ of blood was collected.

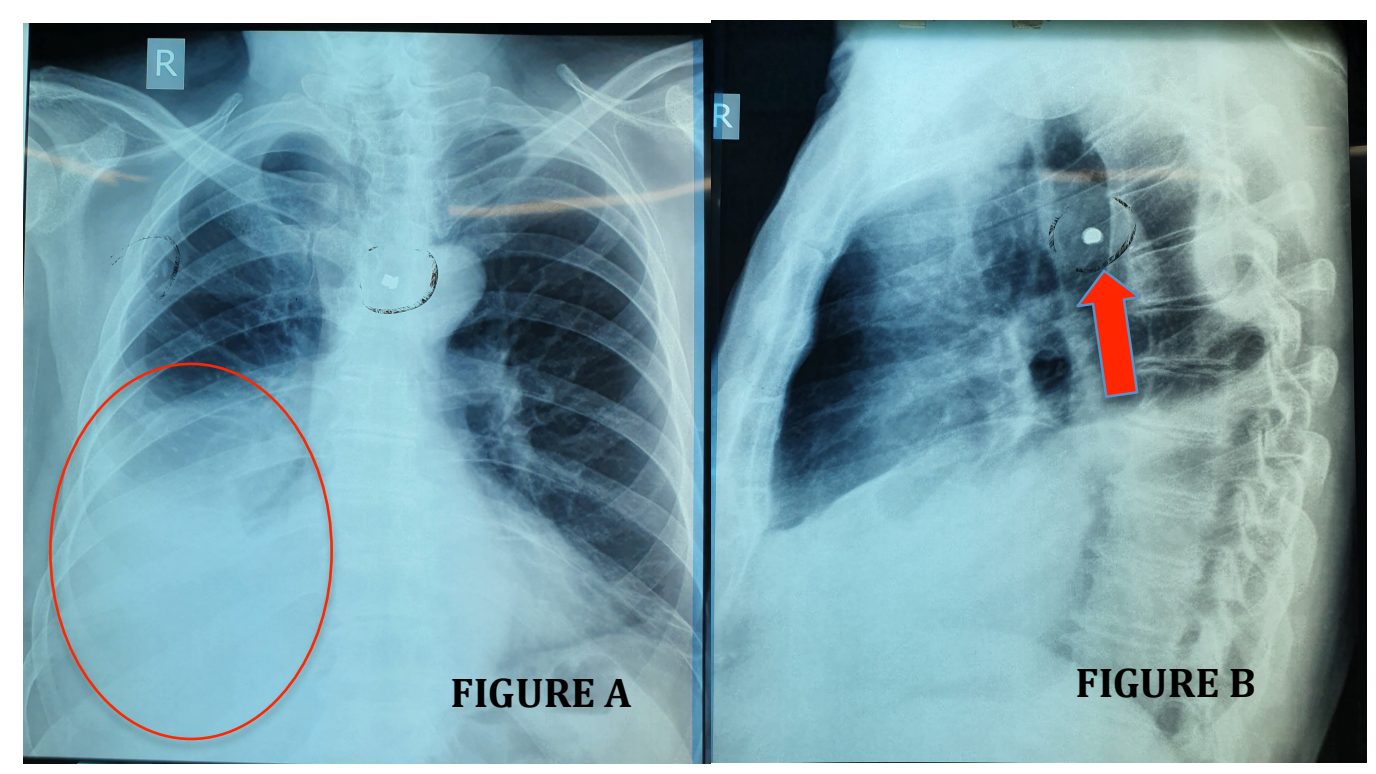

Figure 1. A Anterior-posterior chest $x$-ray in the picture showed a massive fluid accumulation on the right side of the chest, suggested hemothorax (red circle mark). Figure B Lateral chest X-ray in the image showed a foreign body in the posterior mediastinum (red arrow mark) 
Follow-up in 3 days showed there was only $50 \mathrm{ml}$ blood left, and a chest tube was removed. Chest $\mathrm{Ct}-\mathrm{Scan}$ was done to evaluate bullet position before thoracotomy. Chest $\mathrm{Ct}$ Scan result showed a foreign body with size $7,482 \mathrm{~mm} \times 6,626 \mathrm{~mm}$ in posterior mediastinum behind the aortic arch in front of the thoracic vertebrae corpus 4 (T4) - thoracic vertebrae corpus 5 (T5) (Figure 2.1-2.3). There was also moderate hemothorax with a volume of around $200 \mathrm{cc}$ - thoracotomy with posterolateral approach was done with $\mathrm{C}$-arm as guidance for bullet position during operation. The advantages of using this procedure are: achieving maximum exposure to intrathoracic organs for almost all thoracic surgery procedures and beneficial when used in reoperation and complex procedures. The operation is done carefully to prevent the rupture of the aortic arch. A bullet with a size of $5 \mathrm{~mm}$ (Figure 2.4-2.5) was extracted successfully from the chest, and the patient hemodynamic was stable. Seven days postoperatively, the patient was discharged from the hospital without any complications and stable hemodynamic. The patient went to the outpatient department for follow-up one week after.
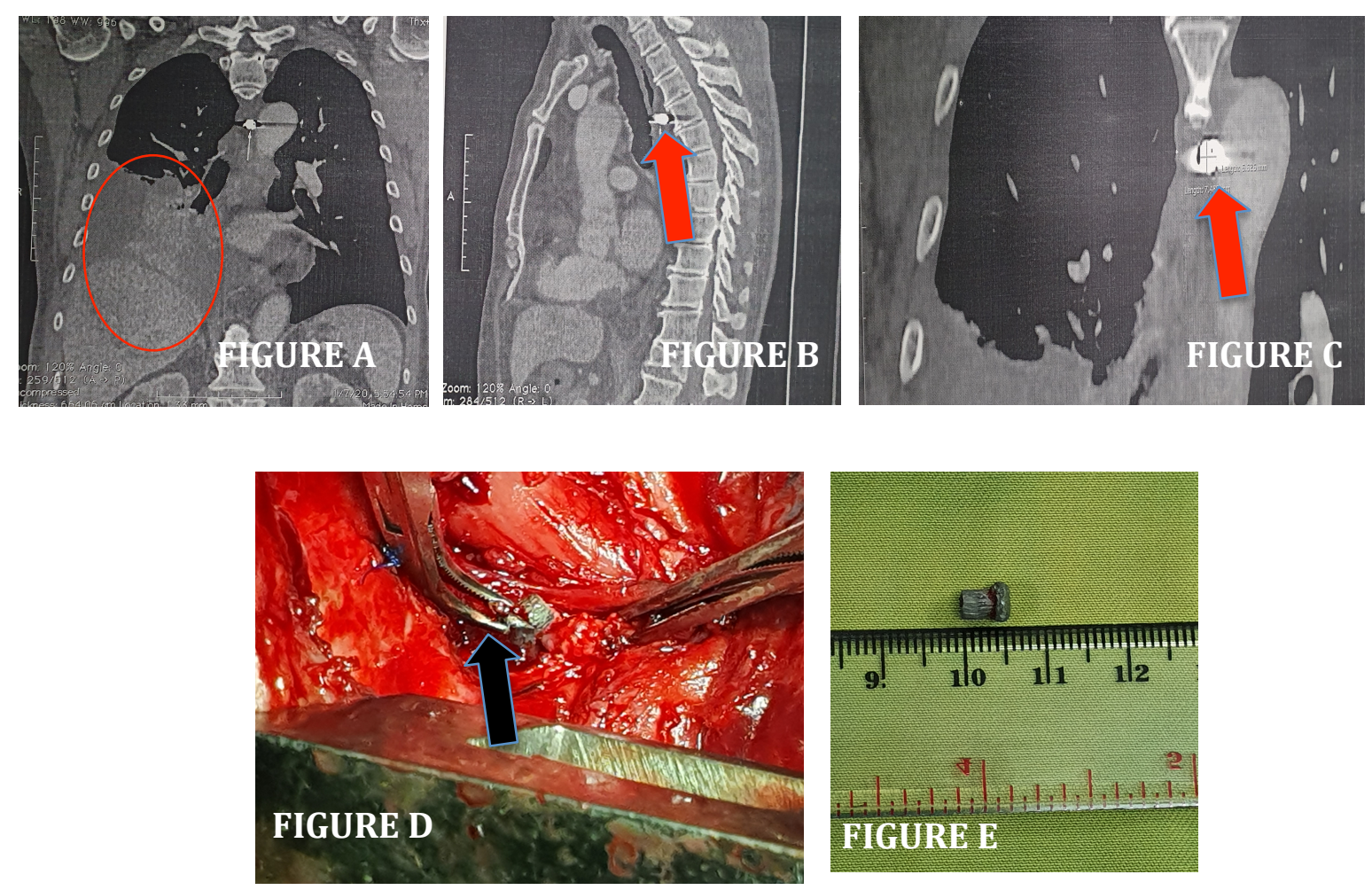

Figure 2. A Chest CT-Scan showed a fluid accumulation on the right chest (red circle mark). Figure B Lateral chest CT-Scan showed a foreign body behind the aortic arch. In front of corpus vertebrae thoracic 4 (T4) - thoracic 5 (T5) (red arrow mark) Figure C A bullet with size 7,482 $\mathrm{mm}$ x 6,626 mm. (red arrow mark) Figure D A bullet extracted from the chest (black arrow mark). Figure E The $5 \mathrm{~mm}$-sized bullet. 


\section{DISCUSSION}

The geriatric population is the fastestgrowing age group nowadays, and trauma to this population accounts for significant admission to the hospital. In Indonesia, based on Badan Pusat Statistik (BPS) data, geriatric has reached 25 million in numbers or $9.60 \%$ of the total population. ${ }^{11}$ Chest trauma in geriatric patients poses a significant challenge to the traumatic surgeon. In chest trauma, age is one of the significant predictors in mortality and morbidity numbers. Standard triage criteria used for the general population may be misleading in the elderly. ${ }^{7}$ Diagnoses can be delayed, and they do not tolerate complications as well as their younger counterparts. anatomical and physiological changes causes by the degenerative process lead to increased morbidity and mortality in the elderly, around 28\%. ${ }^{12}$ McMahon DJ et al. showed that every one-year addition on a patient with age over 65 years old, the possibility to die after trauma increase by more than $6 \%{ }^{13}$ Geriatric patients with comorbidities and decreased sensitivity of several drugs also posed a challenge in resuscitation. The majority of geriatric patients presenting to hospital after receiving trauma are caused by blunt trauma, however a small but significant percentage sustains penetrating trauma. ${ }^{14-15}$ Some studies showed that outcomes after trauma in geriatric are worse than in younger age. The study by Roth et al. showed that following penetrating trauma, the older patient had a more prolonged ICU and hospital stays compared to their younger counterparts. ${ }^{16}$ The study by Nagy et al. in 85 elderly patients compared to 85 young patients with penetrating trauma also showed that elderly sustaining penetrating trauma arriving alive to the hospital is as likely to survive as younger patients but have more comorbidities, as well as longer ICU and hospital stays. ${ }^{17}$ The mortality rate in penetrating trauma remains constant until the age of 55 and increasing after that, according to the study by Ottochian et al. ${ }^{18}$

Hemothorax is one of the most frequent consequences of thoracic trauma. Intrapleural and extrapleural injuries can cause it. Hemothorax can be diagnosed in patients receiving chest trauma with unstable hemodynamic. On physical examination, chest percussion revealed a dull sound on the involved side and showed a fluid-filled chest. Auscultation may indicate a decrease in broncho-pulmonary sound. The chest radiograph showed massive fluid accumulation on the involved side of the chest, suggesting hemothorax. In supine condition, hemothorax on chest radiograph reveals a cloudy view that is hard to assess. Some studies reveal the amount of blood volume estimated in thoracic cavities in cloudy chest x-ray counted from intercostal space. One intercostal space can contain 
around 200-250 cc blood volume. Blood that enters the pleural cavity is exposed to the motion of the diaphragm, lungs, and other intrathoracic structures. Fluid accumulation in the chest cavity can inhibit lung expansion. In this case, the patient had cyanosis that probably caused by lung compression by hemothorax. ${ }^{9}$

Treatments of hemothorax are based on its severity. It depends on the accumulation of fluid volume on the chest involved. Surabaya standard divided hemothorax into three classifications:

1. Mild hemothorax with $300 \mathrm{cc}$ fluid

2. Moderate hemothorax with $300-800$ fluid

3. Massive hemothorax with $>800 \mathrm{cc}$ fluid

Treatment for mild hemothorax is conservative or thoracentesis, while moderate hemothorax using chest tube insertion and WSD as a treatment. Thoracotomy exploration is indicated for hemothorax with fluid volume $>800$ cc. $^{19}$ In this case, the patient had 500 cc fluid, classified as moderate hemothorax, which needs a chest tube and WSD. Establishing a correct diagnosis remains the most important thing before chest tube insertion. The best timing for chest tube insertion in the thoracic trauma case is based on clinical signs and symptoms and associated injuries. Good skill in the physical examination is needed. Chest examination included inspection, palpation, percussion, and auscultation that has high sensitivity and specificity (90\% and 98\%, respectively). ${ }^{2} \quad \mathrm{~A}$ repeated examination is important. Chest radiography can be performed rapidly. CT Scan might also be useful, but it only can be done on stable hemodynamic patient. There are two main sites of chest tube insertion: 1) The ventral approach on the 2 nd - 3rd intercostal space on the mid-clavicular line (Monaldi); 2) Lateral approach on the 4th -6 th intercostal space on anterior axillary line (Bulau). ${ }^{20,21}$

A study by Huber-Wagner et al. revealed that there were no differences in both techniques. ${ }^{22}$ Although operators usually preferred the Bulau approach, both techniques were considered safe and effective in chest trauma situations.

Thoracic foreign bodies are classified into three types: type-I (Aspiration), type II (Trauma or accident, type III (Iatrogenic). Type II thoracic traumas may occur after a laceration or an injury by the gun explosion. ${ }^{23}$ Complications associated with metallic foreign bodies in the thoracic cavity such as hemothorax, pneumothorax, obstructive pneumonitis, and atelectasis. Calcific fibrothorax results of previous hemothorax can occur in the delayed phase. Chronic empyema can arise if there is a foreign body in the pleural cavity. There are some indications in bullet removal of thoracic trauma, including intra-articular missile, abscess or sepsis, migrating or embolizing missile, lead poisoning, and exploration. A thoracotomy procedure can do bullet removal 
in the thoracic cavity. Thoracotomy procedure indicated in some conditions such as hemothorax $(>1500 \mathrm{~mL}$ initial blood loss, bleeding $>250 \mathrm{~mL} / \mathrm{h}$ ), pneumomediastinum associated with tracheal, bronchial, and esophageal injuries. $^{24-26}$ In this case, the cardiothoracic surgeon chooses to remove the bullet from the chest, considering the patient's age, which belongs to the geriatric population that has a higher risk of infection caused by a foreign body (bullet).

\section{CONCLUSION}

Penetrating chest injury, especially in geriatric, that is caused by high-velocity gunshot injury, poses a significant challenge for the surgeon. Removal of the bullet in the chest is recommended in geriatric patients to prevent further infection. A good physical examination is needed in chest trauma cases in the elderly, including inspection, palpation, percussion, and auscultation. If hemothorax is diagnosed, the treatment must depend on its severity. From the Surabaya standard, an immediate chest tube should be inserted in moderate hemothorax. The chest tube can be inserted in Monaldi or Buleu. In this case, seven days postoperatively, the patient was discharged from the hospital without any complications and stable hemodynamic. The patient went to the outpatient department for follow-up one week after.

\section{REFERENCES}

1. Onat, S., Ulku, R., Avci, A., Ates, G. \& Ozcelik, C. Urgent thoracotomy for penetrating chest trauma: Analysis of 158 patients of a single center. Injury 42, 900-904 (2011).

2. Ludwig, C. \& Koryllos, A. Management of chest trauma. $J$. Thorac. Dis. 9, S172-S177 (2017).

3. Unsworth, A., Curtis, K. \& Asha, E. E. Treatments for blunt chest trauma and their impact on patient outcomes and health service delivery. Scand. $J$. Trauma. Resusc. Emerg. Med. 23, 1-9 (2015).

4. Ekpe, E. E. \& Eyo, C. Determinants of mortality in chest trauma patients. Niger. J. Surg. Off. Publ. Niger. Surg. Res. Soc. 20, 30-34 (2014).

5. Karmy-Jones, R. et al. Urgent and Emergent Thoracotomy for Penetrating Chest Trauma. J. Trauma - Inj. Infect. Crit. Care 56, 664-668 (2004).

6. Ilhan Inci, C. et al. Penetrating chest injuries: Unusually high incidence of high-velocity gunshot wounds in civilian practice. World J. Surg. 22, 438-442 (1998).

7. Benjamin Christie, D., Nowack, T., Drahos, A. \& Ashley, D. W. Geriatric chest wall injury: Is it time for a new sense of urgency? J. Thorac. Dis. 11, S1029-S1033 (2019). 
8. Qaqish, T. R., Coleman, J. \& Katlic, M. Geriatric Trauma and Acute Care Surgery. Geriatr. Trauma Acute Care Surg. (2018). DOI:10.1007/978-3-31957403-5

9. Moore, C. et al. Successful treatment of massive hemothorax with class IV shock using aortography with transcatheter embolization of actively bleeding posterior left intercostal arteries after penetrating left chest trauma: A case for the hybrid OR. Int. J. Surg. Case Rep. 48, 109-112 (2018).

10. Yi, J. H. et al. Management of traumatic hemothorax by closed thoracic drainage using a central venous catheter. J. Zhejiang Univ. Sci. $B$ 13, 43-48 (2012).

11. Ika Maylasari, S.ST., M. S. et al. Statistik Penduduk Lanjut Usia 2019. xxvi + 258 halaman (2019).

12. Arslan, B. Geriatric trauma. Curr. Opin. Crit. Care 21, 520-526 (2015).

13. McMahon, D. J., Schwab, C. W. \& Kauder, D. Comorbidity and the elderly trauma patient. World J. Surg. 20, 1113-1120 (1996).

14. Demetriades, D. \& Velmahos, G. C. PENETRATING INJURIES OF THE CHEST : INDICATIONS FOR OPERATION. SAGE Journals 91, 4145 (2002).

15. van Waes, O. J. F., van Riet, P. A., van Lieshout, E. M. M. \& Hartog, D. D. Immediate thoracotomy for penetrating injuries: Ten years' experience at a Dutch level I trauma center. Eur. J. Trauma Emerg. Surg. 38, 543-551 (2012).

16. Roth, B. J. et al. Penetrating trauma in patients older than 55 years: A casecontrol study. Injury 32, 551-554 (2001).

17. Nagy, K. K. et al. Prognosis of penetrating trauma in elderly patients: A comparison with younger patients. $J$. Trauma - Inj. Infect. Crit. Care 49, 190-194 (2000).

18. Ottochian, M. et al. Does age matter? The relationship between age and mortality in penetrating trauma. Injury 40, 354-357 (2009).

19. Puruhito. Ilmu Bedah Toraks Primer, Kardiak, dan Vaskular: Buku Ajar. (Airlangga University Press, 2013).

20. Boersma, W. G., Stigt, J. A. \& Smit, H. J. M. Treatment of haemothorax. Respir. Med. 104, 1583-1587 (2010).

21. Bertoglio, P. et al. Chest drain and thoracotomy for chest trauma. $J$. Thorac. Dis. 11, S186-S191 (2019).

22. Huber-Wagner, S. et al. Emergency chest tube placement in trauma careWhich approach is preferable? Resuscitation 72, 226-233 (2007).

23. Kim, T. J., Goo, J. M., Moon, M. H., Im, J. G. \& Kim, M. Y. Foreign Bodies in the Chest: How Come They Are Seen in Adults? Korean J. Radiol. 2 , 87-96 (2001). 
24. Dienstknecht, T. et al. Indications for bullet removal: Overview of the literature and clinical practice guidelines for European trauma surgeons. Eur. J. Trauma Emerg. Surg.

38, 89-93 (2012).

25. Mintz, Y., Gross, M., Rivkind, A. \&

Eliashar, R. Retained thoracic missile:

Should the bullet be removed? $J$.

Trauma - Inj. Infect. Crit. Care 54, 418 (2003).

26. Erikci, V. S., Mert, M. \& Özdemir, T.

A Bullet in the Thoracic Wall

Following Gun Shot Wound : A Case

Report and Review of Literature. 2, $7-$ 9 (2019). 